\title{
Application of Ultraviolet Light in Dental Identification of Avalanche Victims
}

\author{
Nitin Kumar Agrawal, ${ }^{1}$ Samarika Dahal, ${ }^{1}$ Harihar Wasti, ${ }^{2}$ Alistair Soon ${ }^{3}$
}

'Department of Dentistry, Institute of Medicine, Kathmandu, Nepal, '2Department of Forensic Medicine, Institute of Medicine, Kathmandu, Nepal, ${ }^{3}$ Health Support, Queensland Forensic and Scientific Services, Queensland, Australia.

\begin{abstract}
In any disaster, it becomes important to identify the deceased for ethical, social and legal causes. Out of the numerous methods of identification, dental comparison is considered to be one of the scientific methods in a Disaster Victim Identification process. The two victims of avalanche in Nepal were identified using dental comparison. The two bodies brought for examination were unidentifiable visually. To aid identification of tooth coloured restorations, ultraviolet light was used. The ultraviolet light made the tooth coloured restorations appear distinct from the adjacent tooth structure in one of the cases. This helped in post-mortem charting of dental examination with greater accuracy. When the ante-mortem dental records and the post-mortem dental findings were compared, positive identification was made for both the cases. The bodies were then handed over to their respective kin. These cases highlighted the importance of ultraviolet light in post-mortem dental examination and the significance of forensic dentistry in identification process.

Keywords: Disaster Victim Identification; forensic dentistry; Nepal; ultraviolet light.
\end{abstract}

\section{INTRODUCTION}

Identification of a deceased person is important for legal, ethical, religious and social reasons. ${ }^{1}$ The Identification of dead bodies becomes essential in cases of mass disasters, which may be caused by natural events, for example flooding, earthquake; or man-made events, such as terrorist attacks or plane crashes. ${ }^{2}$

The tooth is considered to be the hardest and the most durable structure of human body. It can resist heavy impact, burning or the post-mortem taphonomic process, and therefore, the tooth becomes a reliable tool in identification of the deceased when bodies become visually unidentifiable. The importance of teeth has been shown by Dahal et al. ${ }^{3}$ when most of the Sita Air Crash deceased were identified on dental basis. Similarly, in 2007, Campobasso et al. ${ }^{4}$ utilized dental comparison and frontal sinus comparison in identification of two burnt bodies.

Silver amalgam restorations or gold restorations are metallic restorations that can be easily spotted in postmortem dental examination, thus making the process of identification easier. On the other hand, tooth coloured fillings, such as composite resins, blend well with the adjacent tooth structure, thus making their identification difficult. With the decline in use of metallic restorations, and the increase in use of composite restorations for aesthetic purpose, post-mortem dental examination becomes more difficult. ${ }^{5}$

Composite restoration owes a unique characteristics of fluorescence, like dental porcelain. This fluorescence is considered due to inclusion of rare earth compounds in the filler of the resin matrix portion. ${ }^{6}$ When the composite restoration is exposed to the ultraviolet light, it fluoresces, making it distinct to the adjacent tooth structure. ${ }^{5}$ Ultraviolet Light-Emitting Diode flashlights can be used as an adjunct in post-mortem dental examination to aid in identification of composite restorations.

\section{CASES}

$13^{\text {th }}$ October 2014, an avalanche at Nepal's Thorun La pass (Annapurna hiking circuit) claimed the lives of many Nepalese and Foreign nationals. Since the incident took place in 2014, two bodies were subsequently recovered in April 2015, and they were brought to the Department 
of Forensic Medicine,Tribhuvan University Teaching Hospital, for identification purposes. The passports of these deceased victims were found in their clothing, and based on the passport details, ante-mortem dental data was obtained from their family members. Postmortem dental examination on these two victims was then carried out by two forensic odontologists to ensure quality assurance. The following describes the dental comparison process of these two victims.

\section{CASE 1}

The body was mummified and was in no condition to be visually identified (Fig. 1). Post-mortem dental examination was carried out after cleaning the oral cavity. There were two solitary amalgam restorations present on the occlusal surface of both teeth 16 and 26. An occlusal amalgam restoration was also present on tooth 46. Intra-oral photographs were taken. Ultraviolet light was used to screen for any tooth coloured restorations. All post-mortem dental findings were recorded in a pink INTERPOL DVI (Disaster Victim Identification) form. The ante-mortem dental records were entered in the yellow INTERPOL DVI form. On reconciliation between the antemortem and post-mortem dental data, identification of the deceased was established.

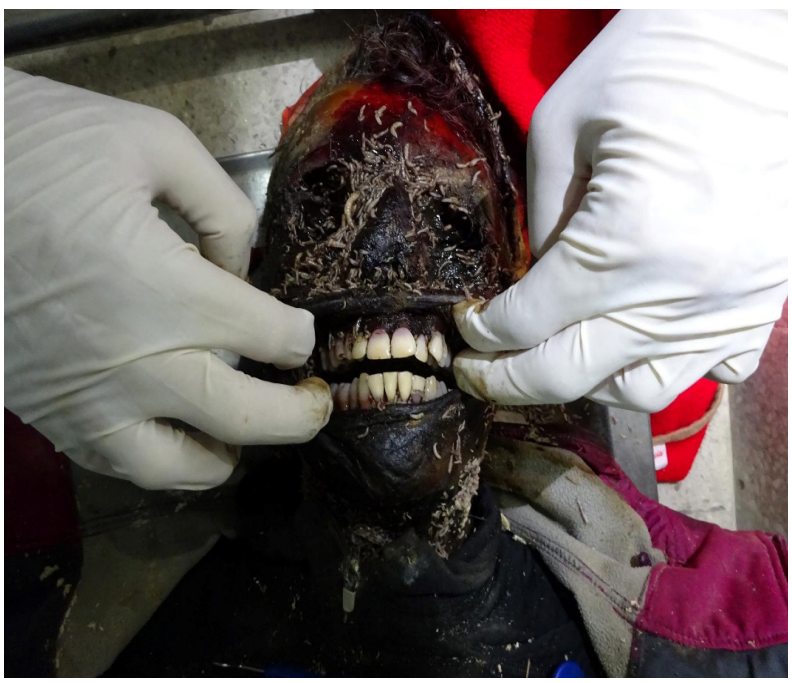

Figure 1. Composite restorations on 15 and 14 showing fluorescence under UV light.

\section{CASE 2}

The condition of the body was similar to Case 1. Visual identification was not possible, due to mummification. Post-mortem dental examination was carried out after cleaning the oral cavity. As previously noted in Case 1, ultraviolet light was used to screen for any tooth coloured restorations. Unlike Case 1, ultraviolet light revealed several tooth coloured fillings that were otherwise not visible. It was noted that there were composite restorations on teeth 15 and 14 , and the distinct appearance of these restorations can be seen under ultraviolet light (Fig. 2). Figure 3 shows the appearance of composite restorations on teeth 15 and 14 without ultraviolet light. On this deceased person, there were fixed orthodontic retainer wires attached with composite restorations on the palatal surfaces of teeth $12,11,21$, and 22 , and also the lingual surfaces of $32,31,41$, and 42 . Intra-oral photographs were taken. The post-mortem dental findings were entered in the pink INTERPOL DVI form. The ante-mortem dental records were entered in the yellow INTERPOL DVI form. On comparison with ante-mortem dental findings, the positive identification of the deceased was established.
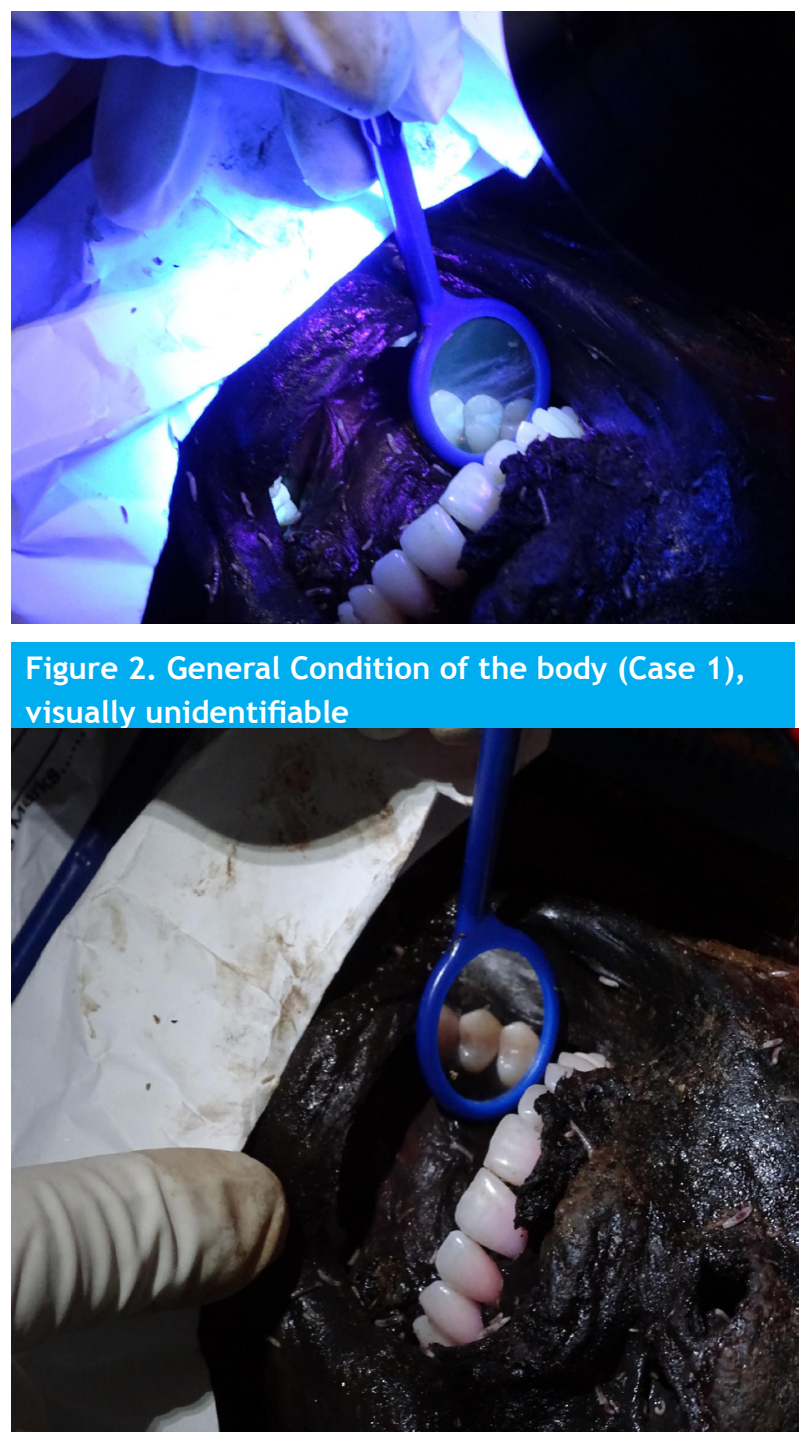

Figure 3. Composite restorations on 15 and 14 under normal light 


\section{DISCUSSION}

Dental comparison is considered as one of the primary identifiers in identification of disaster victims. ${ }^{7}$ The other primary identifiers are fingerprints and DNA comparison. The tooth is considered to be the most durable human tissue, and it can serve as an evidence basis for identification of victims' undergone skeletonization, decomposition, or dismemberment. ${ }^{8}$

The principle of dental identification is based on comparison of ante-mortem and post-mortem dental data. The uniqueness of concordant ante-mortem and post-mortem dental features helps in establishing identification. ${ }^{9}$ It is therefore important for the examining dentist to collect as much information as possible. It is important to record all post-mortem dental findings, such as dental restorations and other dental work, during the post-mortem dental examination of the deceased person.

Bux et al. ${ }^{10}$ concluded that even an experienced dentist can fail to identify high quality tooth-coloured dental restorations, and to facilitate post-mortem dental examination, they recommended removal of the victims' jaws. They also recommended the use of additional tools such as dental radiographs, phosphoric acid etching, or the use of ultraviolet light.

The two cases presented above described that both the victims were not visually recognisable due to the postmortem changes. The loss of rigor mortis in both cases allowed easy access to the deceased's oral cavity, and no forceful mouth opening was required. Sada and Arroyo in $1985^{11}$ discussed that forceful mouth opening during postmortem dental examination can lead to alteration of oral structures. Jaw removal was not recommended in these cases, as there were no issues with access to the oral cavity. Clarke ${ }^{12}$ in his report in 2001, recommended that the body parts should not be removed for identification purposes, unless it is the last resort. Removal of jaws can also sometimes lead to facial disfigurement, and could hamper any post-mortem investigations, if required at a later stage. ${ }^{13}$

In these two cases, we used Ultraviolet light to aid the identification of tooth coloured restorations. Composite restorations in Case 2 appeared to fluoresce under UV light, and were easily identified. This demonstrates the importance of ultraviolet light in assisting the identification of tooth coloured restorations which otherwise would had been difficult to identify under normal lighting conditions. Guzy and Clayton in $2013^{5}$ demonstrated the value of ultraviolet light as an adjunct to visual examination in the two cases of identification. Hermanson et al. ${ }^{14}$ strongly recommended use of ultraviolet illumination in forensic dental examination, as it can help in identification of composite restorations. This technique helps in preparation of a detailed post-mortem dental charting, which can be used to compare with the ante-mortem dental records.

The importance of forensic odontology in victim identification can be clearly observed in these cases, and has been stressed by various authors. , $^{3,9,15}$

\section{CONCLUSIONS}

We strongly recommend the use of ultraviolet light as an adjunct tool for forensic dental examination, as ultraviolet light helps in the identification of composite restorations, as some of them can be difficulty to identify in normal lighting conditions.

\section{ACKNOWLEDGEMENTS}

We would like to thank faculty members of Department of Forensic Medicine, Maharajgunj Medical Campus, IOM, TUTH for their constant support.

\section{REFERENCES}

1. Dagalp R, Aka P, Canturk N, Kedici I. Age estimation from fetus and infant tooth and head measurements. Int J Legal Med. 2013;128(3):501-8.[Link]

2. Kolude B, Adeyemi B, Taiwo J, Sigbeku O, Eze U. The role of forensic dentist following mass disaster. Ann Ib Postgrad Med. 2011;8(2):111-7. [Full Article]

3. Dahal S, Agrawal NK, Shrestha PK. Role of dentists in disaster victim identification of Sita air crash, Nepal. JIOM.2014;36(2):97-101.[Link]

4. Campobasso C, Dell'Erba A, Belviso M, Di Vella G. Craniofacial identification by comparison of antemortem and postmortem radiographs. AmJ Forensic Med Pathol. 2007;28(2):182-6.[Link]

5. Guzy G, Clayton M. Detection of composite resin restorations using an ultraviolet light-emitting diode flashlight during forensic dental identification. Am J Forensic Med Pathol. 2013;34(2):86-9.[PubMed]

6. Uo M, Okamoto M, Watari F, Tani K, Morita M, Shintani A. Rare Earth Oxide-containing Fluorescent Glass Filler for Composite Resin. Dental Materials Journal. 2005;24(1):49-52.[Full Article] 
7. Berketa J, James H, Lake A. Forensic odontology involvement in disaster victim identification. Forensic Sci Med Pathol. 2011;8(2):148-56.[PubMed]

8. Avon SL. Forensic odontology: the roles and responsibilities of the dentist. J Can Dental Assoc. 2004 Jul-Aug;70(7):453-8.[PubMed]

9. Valenzuela A, Martin-de las Heras S, Marques T, Exposito $\mathrm{N}$, Bohoyo J. The application of dental methods of identification to human burn victims in a mass disaster. Int J Legal Med. 2000;113(4):236-9.[PubMed]

10. Bux R, Heidemann D, Enders M, Bratzke H. The value of examination aids in victim identification: a retrospective study of an airplane crash in Nepal in 2002. Forensic Sci Int. 2006;164(2-3):155-8. [Link]

11. Sada J, Arroyo G. Identification through odontologic study. Tribuna Medica. 1985;11:1-6.
12. Public inquiry into the identification of victims following major transport accidents: report of Lord Justice Clarke [Internet]. Norwich:Crown; 2012[cited 2016 November 10].[Full Text]

13. Fereira J, Ortega A, Avila A, Espina A, Leendertz R, Barrios F. Oral autopsy of unidentified burned human remains. A new procedure. Am J Forensic Med Pathol. 1997;18(3):306-11.[PubMed]

14. Hermanson A, Bush M, Miller R, Bush P. Ultraviolet illumination as an adjunctive aid in dental inspection. J Forensic Sci. 2008;53(2):408-11.[PubMed]

15. Solheim T, Lorentsen M, Sundnes P, Bang G, Bremnes L. The "Scandinavian Star" ferry disaster 1990 -a challenge to forensic odontology. Int J Legal Med. 1992;104(6):33945. 